\title{
A meta-analysis and bioinformatics exploration of the diagnostic value and molecular mechanism of miR-193a-5p in lung cancer
}

\author{
ZU-CHENG XIE, RUI-XUE TANG, XIANG GAO, QIONG-NI XIE, JIA-YING LIN, GANG CHEN and ZU-YUN LI \\ Department of Pathology, First Affiliated Hospital of Guangxi Medical University, Nanning, Guangxi 530021, P.R. China
}

Received August 13, 2017; Accepted February 13, 2018

DOI: $10.3892 / \mathrm{ol} .2018 .9174$

\begin{abstract}
Lung cancer is a leading cause of mortality worldwide and despite recent improvements in lung cancer treatments patient mortality remains high. miR-193a-5p serves a crucial role in the initiation and development of cancer; it is necessary to understand the underlying molecular mechanisms of miR-193a-5p in lung cancer, which may enable the development of improved clinical diagnoses and therapies. The present study investigated the diagnostic value of peripheral blood and tissue miR-193a-5p expression using a microarray meta-analysis. Peripheral blood miR-193a-5p was revealed to be upregulated in patients with lung cancer. The pooled area under the curve (AUC) was 0.67, with a sensitivity and specificity of 0.74 and 0.56 , respectively. Conversely, the peripheral tissue miR-193a-5p expression in patients with lung cancer was significantly downregulated. The pooled AUC was 0.83 , and the sensitivity and specificity were 0.65 and 0.89 , respectively. Through bioinformatics analysis, three Kyoto Encyclopedia of Genes and Genomes (KEGG) terms, pathways in cancer, prostate cancer and RIG-I-like receptor signaling pathway,
\end{abstract}

Correspondence to: Professor $\mathrm{Zu}-Y u n \mathrm{Li}$, Department of Pathology, First Affiliated Hospital of Guangxi Medical University, 6 Shuangyong Road, Nanning, Guangxi 530021, P.R. China

E-mail: li_zuyun_gxmu@163.com

Abbreviations: ERBB2, erb-b2 receptor tyrosine kinase 2; ERBB4, erb-b2 receptor tyrosine kinase 4; NCBP2, nuclear cap binding protein subunit 2; COL1A1, collagen type I alpha 1 chain; PCSK9, proprotein convertase subtilisin/kexin type 9; CSNK2A1, casein kinase $2 \alpha 1$; UBTF, upstream binding transcription factor, RNA polymerase I; PIK3R3, phosphoinositide-3-kinase regulatory subunit; mTOR, mechanistic target of rapamycin kinase; S6K2, serine/threonine protein kinase 2; SROC, summary receiver operating characteristic; LR, likelihood ratio; DAVID, The Database for Annotation, Visualization and Integrated Discovery; GO, gene ontology; KEGG, Kyoto Encyclopedia of Genes and Genomes; PPI, protein-protein interaction; TCGA, The Cancer Genome Atlas; $\mathrm{ROC}$, receiver operating characteristic; $\mathrm{BP}$, biological process; $\mathrm{CC}$, cellular component, MF, molecular function

Key words: microRNA-193a-5p, lung cancer, diagnosis, target genes, bioinformatics were identified as associated with miR-193a-5p in lung cancer. In addition, in lung cancer, six key miR-193a-5p target genes, receptor tyrosine-protein kinase erbB-2 (ERBB2), nuclear cap-binding protein subunit 2 (NCBP2), collagen $\alpha-1(\mathrm{I})$ chain (COL1A1), roprotein convertase subtilisin/kexin type 9 (PCSK9), casein kinase II subunit $\alpha$ (CSNK2A1) and nucleolar transcription factor 1 (UBTF), were identified, five of which were significantly upregulated (ERBB2, NCBP2, COL1A1, CSNK2A1 and UBTF). The protein expression of ERBB2, NCBP2, COL1A1, CSNK2A1 and UBTF was also upregulated. NCBP2 and CSNK2A1 were negatively correlated with miR-193a-5p. The results demonstrated that miR-193a-5p exhibited opposite expression patterns in peripheral blood and tissue. Upregulated peripheral blood miR-193a-5p and downregulated tissue miR-193a-5p may be promising diagnostic biomarkers in lung cancer. In addition, the KEGG terms pathways in cancer, prostate cancer and RIG-I-like receptor signaling pathway may suggest which pathways serve vital roles in lung cancer by regulating miR-193a-5p. In addition, six genes, ERBB2, COL1A1, PCSK9, UBTF and particularly NCBP2 and CSNK2A1, may be key target genes of miR-193a-5p in lung cancer.

\section{Introduction}

Lung cancer ranks second in incidence and first in mortality for both males and females, with an estimated 222,500 new cases and 155,870 deaths in 2017 (1). Unfortunately, the majority of lung cancer patients are diagnosed at an advanced stage and are typically not curable. The current gold standard for lung cancer diagnosis is pathological biopsy, which is an invasive method. With the development of nondestructive testing technology, novel non-invasive methods are needed to monitor and diagnose lung cancer. Though some findings regarding molecular mechanisms in lung cancer have been reported in recent years (2-6), the molecular regulatory mechanisms underlying the initiation and development of lung cancer remain unclear. Therefore, more studies are needed to explore the molecular mechanisms in lung cancer.

MicroRNAs (miRNAs) are highly conserved endogenous small non-coding RNAs approximately 23 nucleotides in length. They exert their effects through posttranscriptional repression in a sequence-specific manner (7). miRNAs have been found to perform crucial biological functions in the initiation and development of cancer (8). In addition, miRNAs 
have begun to be used for the diagnosis and treatment of cancer in recent years (9-11). The clinical significance of miRNA profiles in diagnosis and prognosis has also been evaluated in lung cancer $(12,13)$.

Over the past few years, miR-193a-5p has been found to be involved in multiple cancers, such as esophageal squamous cell carcinoma (14), bladder cancer (15), primary bone tumors (16), osteosarcoma (17), colorectal cancer (18) and endometrioid endometrial adenocarcinoma (19). Some noted pathways such as the PI3K/AKT signaling pathway, PTEN/AKT signaling pathway and mTOR signaling pathway have been implicated in the oncogenesis of different tumors and as therapeutic drug targets (20-24). Some studies have linked miR-193a-5p to lung cancer. For example, in Yu's study, miR-193a-5p was found to block the metastasis of non-small cell lung cancer by inhibiting the ERBB4/PIK3R3/mTOR/S6K2 signaling pathway (25). Similarly, Chen et al (26)revealed that the miR-193a-5p-WT1-E-cadherin axis plays a crucial role in the metastasis of non-small cell lung cancer. However, no study has reported the diagnostic value of miR-193a-5p in lung cancer.

Thus, we attempted to explore the clinical diagnostic significance of miR-193a-5p using a microarray meta-analysis. We also explored the possible molecular mechanisms using bioinformatics analysis. The results of this study could provide insights into the clinical diagnosis of lung cancer and guide future research on the underlying molecular mechanisms.

\section{Materials and methods}

GEO dataset retrieval and data extraction. Lung cancer microarray data published through July 2017 were retrieved from the Gene Expression Omnibus (GEO) database. The retrieval strategies were as follows: (lung OR pulmonary OR respiratory OR bronchi OR bronchioles OR alveoli OR pneumocytes OR 'air way') and (cancer OR carcinoma OR tumor OR neoplas* OR malignan* OR adenocarcinoma) and (MicroRNA OR miRNA OR 'Micro RNA' OR 'Small Temporal RNA' OR 'non-coding RNA' OR ncRNA OR 'small RNA'). Microarray data meeting the following criteria were included: i) The subjects in the datasets included lung cancer patients and corresponding controls; ii) the expression profile of miR-193a-5p in both lung cancer patients and controls was available or calculable; and iii) the number of overall subjects was more than 30 . The expression of miR-193a-5p was extracted from the included datasets and evaluated with means and standard deviations (SD) using SPSS 22.0 (SPSS, Inc., Chicago, IL, USA).

Meta-analysis of the diagnostic value of miR-193a-5p in the GEO datasets. A meta-analysis of the included datasets was conducted to evaluate the diagnostic value of miR-193a-5p using Stata 12.0 software (StataCorp LP, College Station, TX, USA). The pooled effect was estimated as the standard mean difference (SMD) with a 95\% confidence interval (CI). The heterogeneity was measured using a chi-squared test of $\mathrm{Q}$ and $\mathrm{P}$ values. $\mathrm{I}^{2}<50 \%$ or $\mathrm{P}>0.05$ indicated no significant heterogeneity. The publication bias of the datasets was assessed using Begg's funnel plots. A symmetrical funnel plot indicated no obvious publication bias. In addition, summary receiver operating characteristic (SROC) analysis was performed. The pooled diagnostic sensitivity, specificity, odds ratio (OR), positive likelihood ratio (LR) and negative LR were calculated to comprehensively evaluate the diagnostic value of miR-193a-5p.

Identification of miR-193a-5p target genes. Possible target genes of miR-193a-5p were collected using miRWalk 2.0 (http://zmf.umm.uni-heidelberg.de/mirwalk2) (27), which combines 12 prediction databases. Genes predicted by at least 2 databases were selected. We also identified validated target genes of miR-193a-5p using the Tarbase and MitarBase databases. The predicted genes and validated genes were further compared to identify the most significant overlapping miR-193a-5p target genes.

Exploration of the molecular mechanism of miR-193a-5p using bioinformatics analysis. The Database for Annotation, Visualization and Integrated Discovery (DAVID), an online bioinformatics functional enrichment tool for the analysis of large lists of genes $(28,29)$, was used to explore the enriched pathways of the overlapping genes. Gene ontology (GO) and Kyoto Encyclopedia of Genes and Genomes (KEGG) analyses were performed using the DAVID online functional annotation module. Furthermore, to identify hub genes, we used the STRING v10 database (http://string-db.org/) (30) to construct a protein-protein interaction (PPI) network. Genes with connection degrees higher than 3 were considered hub genes.

Validation of hub gene expression using TCGA data. The Cancer Genome Atlas (TCGA) (http://cancergenome.nih. gov) database is one of the largest publicly funded project platforms, providing information regarding cancer-causing genome alterations for more than 30 cancer types (31). To validate the expression of the hub genes, we downloaded the RNA-sequencing data of lung cancer and non-cancerous tissues from the TCGA database. The hub gene expression data in lung cancer and non-cancerous tissues were extracted. The expression values were normalized by $\log 2$ transformation and imported into GraphPad Prism 7.0 (GraphPad Software, Inc., La Jolla, CA, USA). Unpaired Student's t-test and receiver operating characteristic (ROC) curve analyses were conducted to assess the expression differences and clinical significance. Scatter plots were constructed to visualize the differences in miR-193a-5p expression between lung cancer and non-cancerous tissues. In addition, the area under the curve (AUC) was calculated to evaluate the diagnostic capability of miR-193a-5p. A P-value $<0.05$ was considered statistically significant.

Validation of the protein expression of the hub genes. The Human Protein Atlas database (https://www.proteinatlas. org/) provides abundant proteome and transcriptome data for tissues, cells and cancers (32-34). The protein expression of the upregulated hub genes in lung adenocarcinoma (LUAD) and lung squamous cell carcinoma (LUSC) specimens was investigated using the Pathology Altas portal in The Human Protein Atlas database. Antibody staining was analyzed to reflect the protein expression, and only samples with a staining quality of over $75 \%$ were used. Pathological images of typical 
Table I. Characteristics of the GEO datasets included in the meta-analysis.

\begin{tabular}{|c|c|c|c|c|c|c|c|c|}
\hline \multirow[b]{2}{*}{ Author } & \multicolumn{4}{|c|}{ Study information } & \multicolumn{2}{|c|}{ Sample } & \multirow{2}{*}{$\begin{array}{c}\begin{array}{c}\text { Array and } \\
\text { annotation } \\
\text { information }\end{array} \\
\text { Platform }\end{array}$} & \multirow[b]{2}{*}{ Refs } \\
\hline & $\begin{array}{c}\text { Publication } \\
\text { year }\end{array}$ & Country & Sample source & Data source & $\begin{array}{l}\text { Lung cancer } \\
\text { patients }\end{array}$ & $\begin{array}{l}\text { Healthy } \\
\text { controls }\end{array}$ & & \\
\hline Keller et al & 2009 & Germany & Peripheral blood & GSE17681 & 17 & 19 & GPL9040 & (35) \\
\hline Patnaik et al & 2011 & USA & Peripheral blood & GSE27486 & 22 & 32 & GPL11432 & (36) \\
\hline Keller et al & 2011 & Germany & Peripheral blood & GSE31568 & 32 & 67 & GPL9040 & (37) \\
\hline Patnaik et al & 2012 & USA & Peripheral blood & GSE40738 & 82 & 58 & GPL16016 & (38) \\
\hline Keller et al & 2014 & Germany & Peripheral blood & GSE61741 & 73 & 94 & GPL9040 & (39) \\
\hline Godrey et al & 2014 & USA & Peripheral blood & GSE46729 & 24 & 24 & GPL8786 & $(40)$ \\
\hline Leidinger et al & 2015 & Germany & Peripheral blood & GSE68951 & 203 & 12 & GPL16770 & (41) \\
\hline Tan et al & 2010 & China & SCLC/NSCLC & GSE15008 & 182 & 185 & GPL8176 & $(42)$ \\
\hline Nymark et al & 2011 & Finland & NSCLC & GSE25508 & 26 & 26 & GPL7731 & (43) \\
\hline Ohba et al & 2013 & Japan & NSCLC/SCLC & GSE19945 & 55 & 8 & GPL9948 & (44) \\
\hline Bjaanaes et al & 2014 & Norway & LUAD & GSE48414 & 154 & 20 & GPL16770 & $(45)$ \\
\hline Robles et al & 2015 & USA & LUAD & GSE63805 & 32 & 30 & GPL18410 & (46) \\
\hline Gasparini et al & 2015 & Switzerland & NSCLC & GSE72526 & 67 & 18 & GPL20275 & (47) \\
\hline Jin et al & 2015 & China & SCLC/LUAD/LUSC & GSE74190 & 92 & 44 & GPL19622 & (48) \\
\hline Yoshimoto et al & 2016 & Japan & SCLC/LUAD & GSE77380 & 85 & 23 & GPL16770 & (49) \\
\hline
\end{tabular}

NSCLC, non-small cell lung cancer; SCLC, small cell lung cancer.
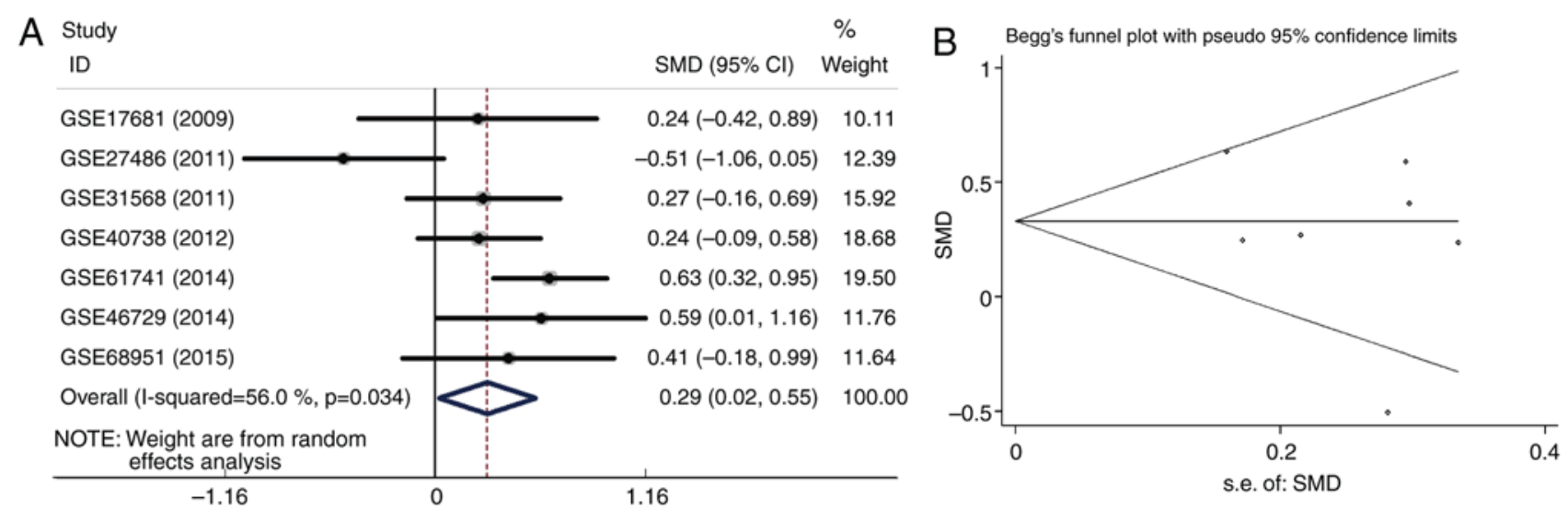

Figure 1. Meta-analysis evaluating the diagnostic value of peripheral blood miR-193a-5p. (A) Forest plot determining the differences in peripheral blood miR-193a-5p expression. (B) Funnel plot determining the publication bias of the included peripheral blood datasets. miR, microRNA; SMD, standard mean difference.

high/medium staining in LUSC cells were chosen for display in this study.

Validation of the correlation analysis between miR-193a-5p and hub genes based on TCGA data. The expression data of miR-193a-5p and the six hub genes in lung cancer were downloaded from the TCGA database. The expression data of both miR-193a-5p and the hub genes were normalized by $\log 2$ transformation. Spearman's correlation analysis was further performed using GraphPad Prism 7.0 (GraphPad Software, Inc.). A Spearman correlation coefficient of $r<0$ indicated a negative correlation between miR-193a-5p and its hub genes.
$\mathrm{P}<0.05$ indicated the statistical significance of the correlation analysis.

\section{Results}

Overview of the included datasets. According to the retrieval criteria, a total of 15 datasets published from 2009 to 2016 were selected, including 7 peripheral blood datasets and 8 tissue datasets. The basic information of the included datasets is provided in Table I (35-49). In the 7 peripheral blood datasets, 453 lung cancer samples and 306 healthy controls were included. In the 8 tissue datasets, 693 lung cancer samples 

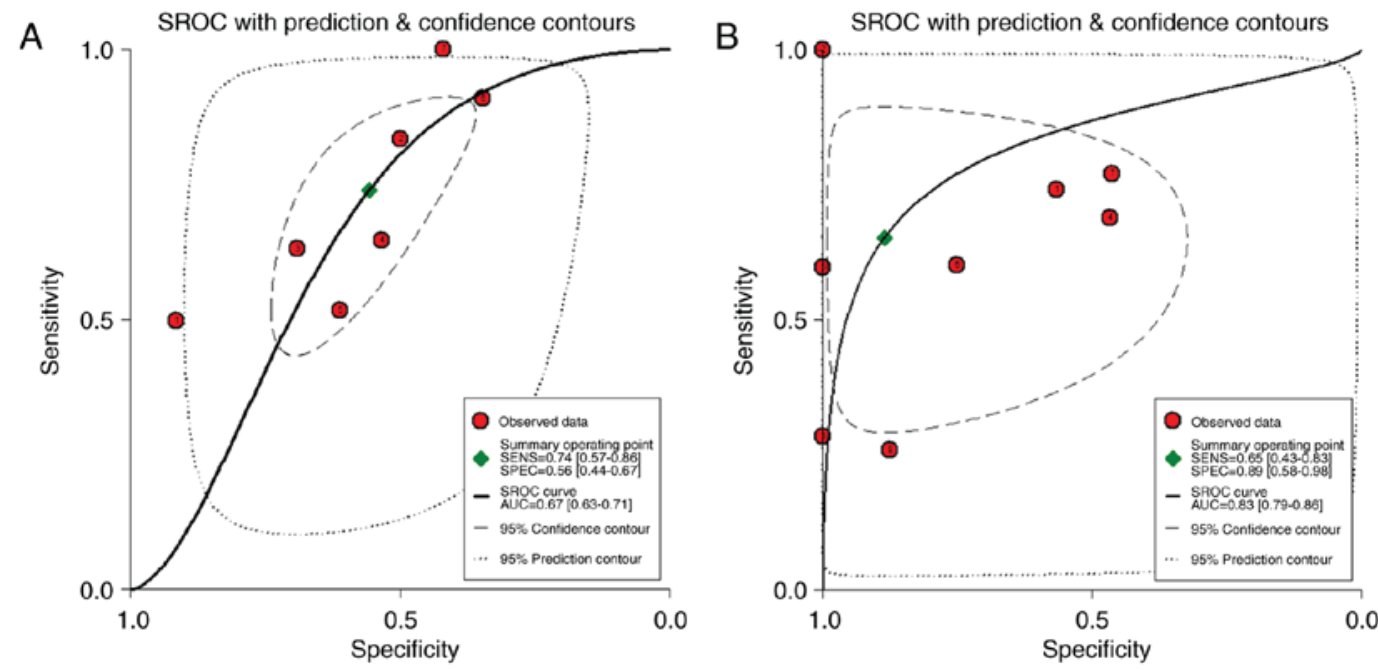

Figure 2. Diagnostic SROC curve of miR-193a-5p in lung cancer. The X-axis represents the specificity, and the Y-axis represents the sensitivity. Each red dot with a number inside represents each included dataset. The green diamond represents the summary operating point. (A) SROC curve of the peripheral blood miR-193a-5p. (B) SROC curve of the tissue miR-193a-5p. SROC, summary receiver operating characteristic; miR, microRNA; SENS, sensitivity; SPEC, specificity; AUC, area under the curve.
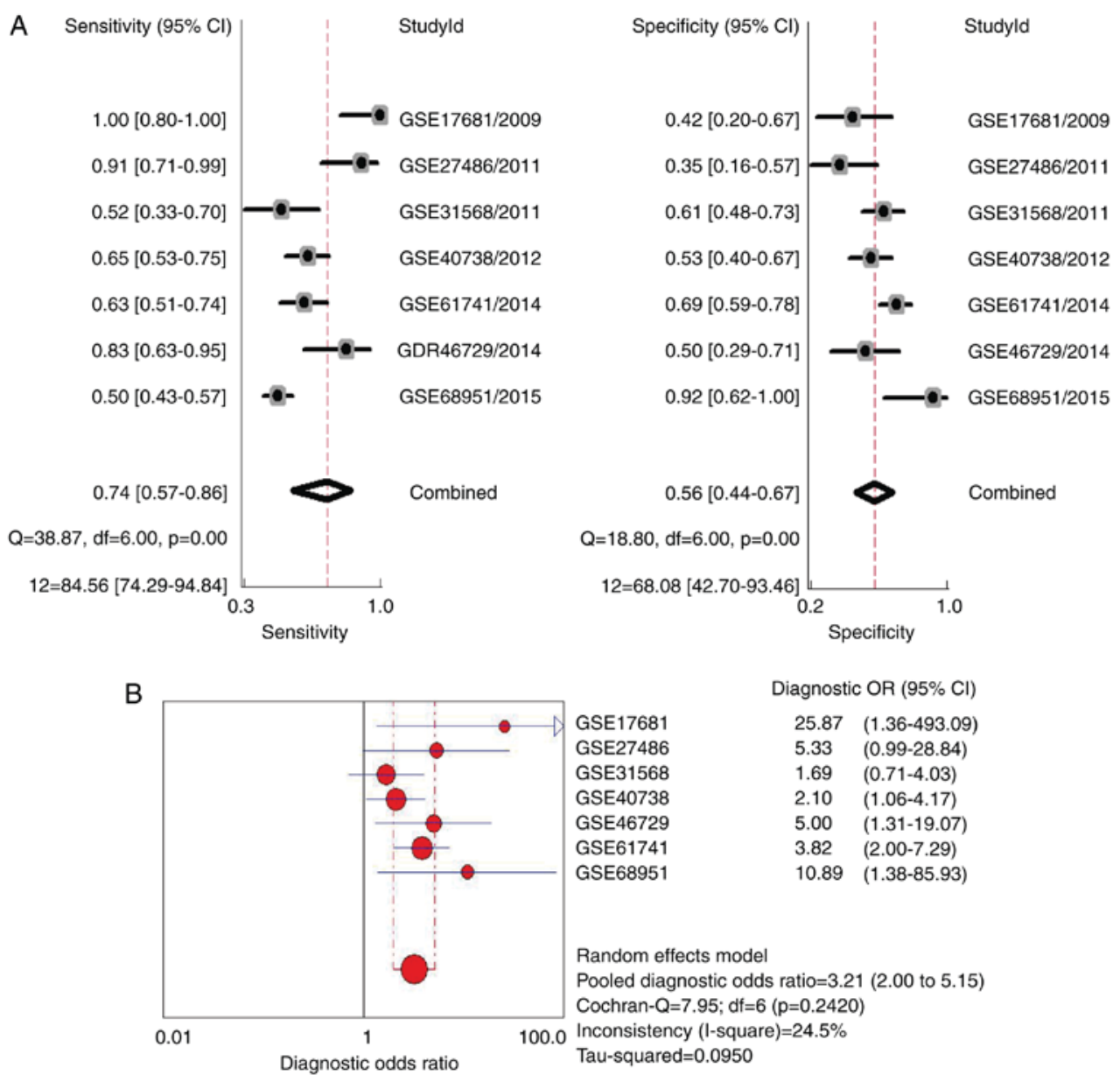

Figure 3. Forest plots evaluating the diagnostic sensitivity, specificity and odds ratio (OR) of peripheral blood miR-193a-5p. (A) Pooled sensitivity and specificity of peripheral blood miR-193a-5p. (B) Pooled diagnostic OR of peripheral blood miR-193a-5p. OR, odds ratio; miR, microRNA.

and 354 healthy controls were included. The miR-193a-5p expression data were normalized by $\log 2$ transformation and extracted as the mean and SD.
Meta-analysis of the diagnostic value of peripheral blood $m i R-193 a-5 p$. The expression of peripheral blood miR-193-5p in the 7 independent peripheral blood datasets was pooled 
A
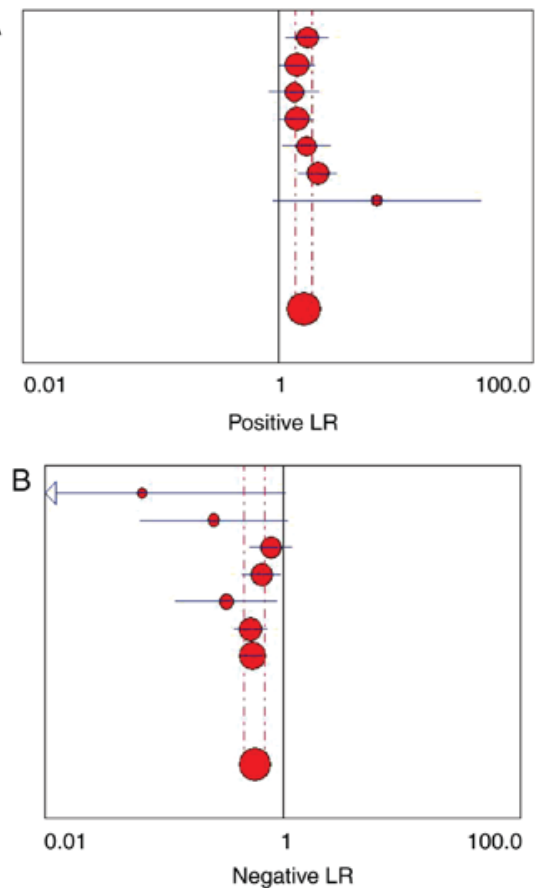

$\begin{array}{lrl} & \text { Positive LR }(95 \% \mathrm{Cl}) \\ \text { GSE17681 } & 1.69(1.15-2.48) \\ \text { GSE27486 } & 1.39(1.01-1.93) \\ \text { GSE31568 } & 1.33(0.84-2.12) \\ \text { GSE40738 } & 1.39(1.01-1.91) \\ \text { GSE46729 } & 1.67(1.08-2.58) \\ \text { GSE671741 } & 2.04(1.44-2.90) \\ \text { GSE68951 } & 5.97(0.91-39.19\end{array}$

Random effects model

Pooled positive LR=1.58 (1.35 to 1.85 )

Cochran- $Q=6.35 ; d f=6(p=0.3849)$

Inconsistency (I-square) $=5.5 \%$

Tau-squared $=0.0025$

$\begin{array}{lrl} & \text { Negative LR }(95 \% \mathrm{Cl}) \\ \text { GSE17681 } & 0.07(0.00-1.05) \\ \text { GSE27486 } & 0.26 & (0.00-1.10) \\ \text { GSE31568 } & 0.79 & (0.52-1.19) \\ \text { GSE40738 } & 0.66 & (0.45-0.97) \\ \text { GSE46729 } & 0.33(0.13-0.89) \\ \text { GSE61741 } & 0.53(0.39-0.74) \\ \text { GSE68951 } & 0.55(0.44-0.68)\end{array}$

Random effects mode

Pooled negative $\mathrm{LR}=0.57$ ( 0.47 to 0.70$)$

Cochran- $Q=8.10 ; \mathrm{df}=6(\mathrm{p}=0.2307)$

Inconsistency (I-square) $=25.9 \%$

Tau-squared $=0.0176$

Figure 4. Forest plots evaluating the pooled positive and negative likelihood ratios (LRs) of peripheral blood miR-193a-5p expression. (A) Pooled positive LR of peripheral blood miR-193a-5p. (B) Pooled negative LR peripheral blood miR-193a-5p. LR, likelihood ratio; miR, microRNA.
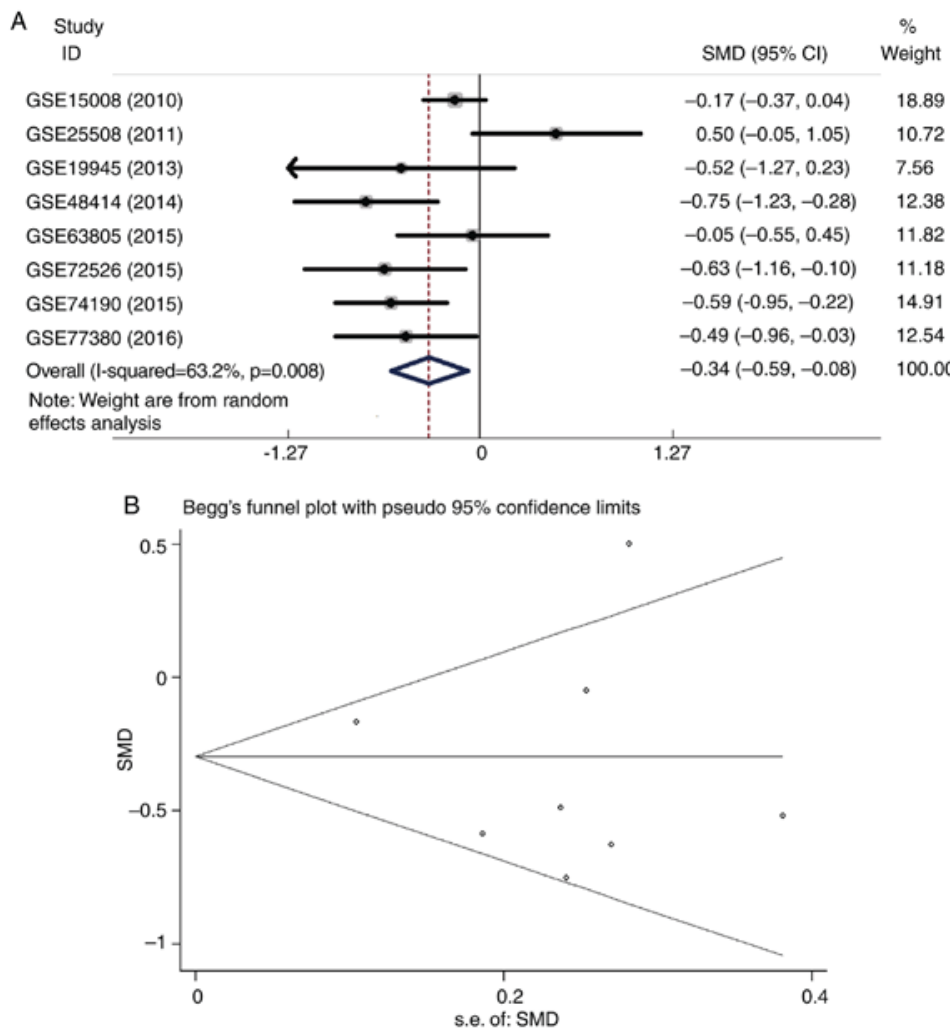

Figure 5. Meta-analysis evaluating the diagnostic value of tissue miR-193a-5p. (A) Forest plot determining the differences in tissue miR-193a-5p. (B) Funnel plot determining the publication bias of the included tissue datasets. miR, microRNA; SMD, standard mean difference.

in a forest plot (Fig. 1A). The SMD was 0.29 (95\% CI: 0.02 to $\left.0.55 ; \mathrm{I}^{2}=56.0 \% ; \mathrm{P}=0.034\right)$. The $\mathrm{SMD}$ was pooled using a random-effects model since heterogeneity was observed $\left(\mathrm{I}^{2}>50 \%\right.$ or P-value $\left.<0.05\right)$. Publication bias was analyzed with a Begg's funnel plot (Fig. 1B). The Begg's funnel plot was basically symmetrical, indicating that no significant publication bias existed among the 7 peripheral blood datasets. SROC analysis was carried out to further examine the diagnostic value of peripheral blood miR-193a-5p. As shown in Fig. 2, the AUC was 0.67 with a $95 \% \mathrm{CI}$ of 0.63 to 0.71 . As shown 

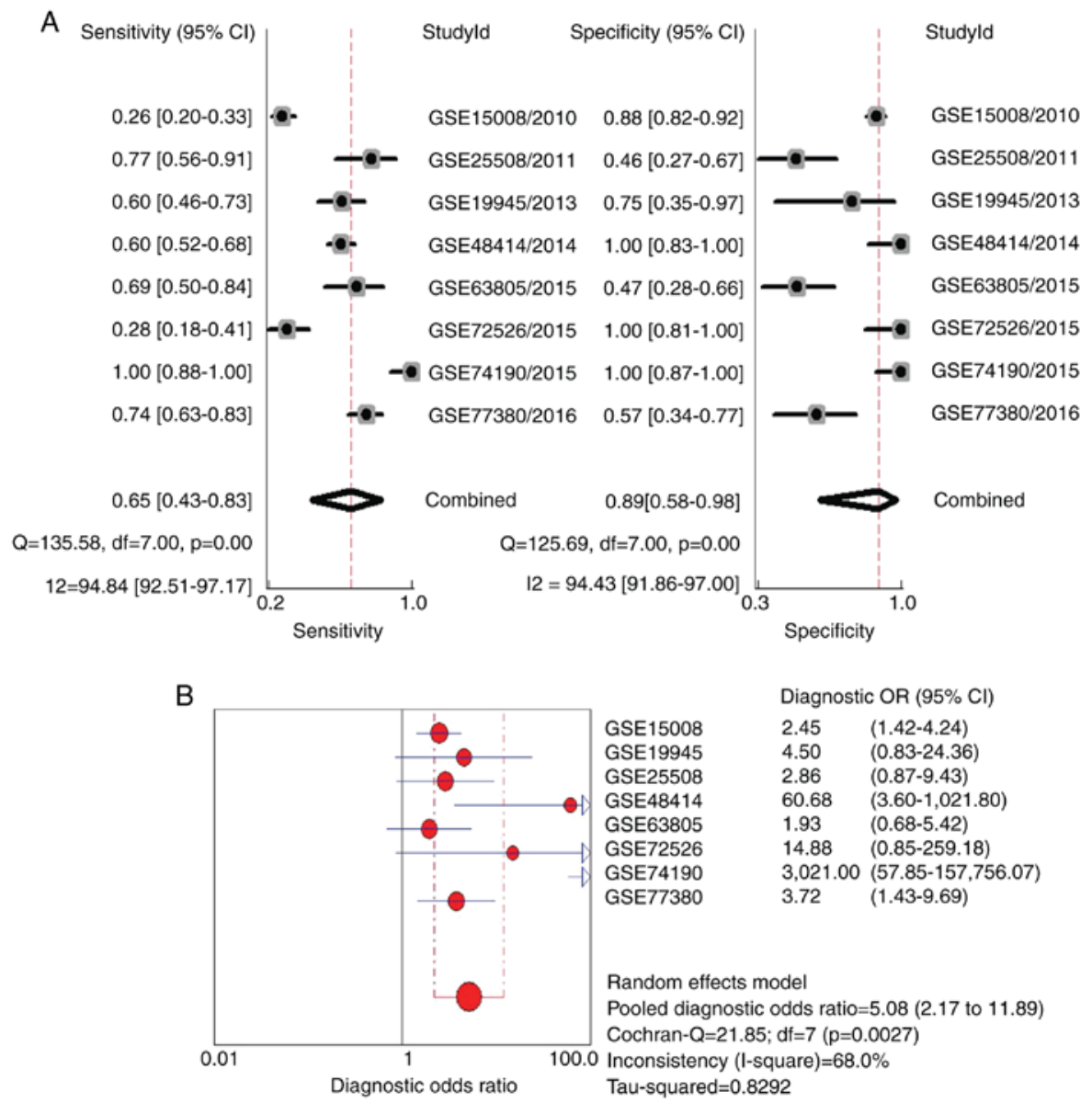

Figure 6. Forest plots evaluating the diagnostic sensitivity, specificity and odds ratio (OR) of tissue miR-193a-5p. (A) Pooled sensitivity and specificity of tissue miR-193a-5p. (B) Pooled diagnostic OR of tissue miR-193a-5p. OR, odds ratio; miR, microRNA.
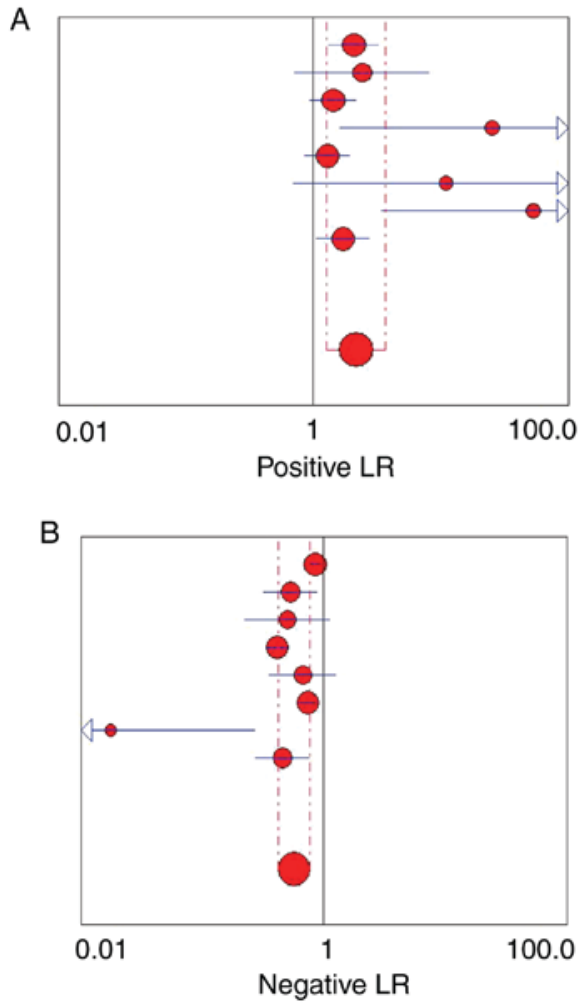

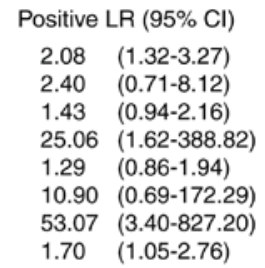

Random effects model

Pooled positive LR=2.15 (1.17 to 3.64 )

Cochran- $\mathrm{Q}=27.02 ; \mathrm{df}=7$ ( $\mathrm{p}=0.0003)$

Inconsistency (I-square) $=74.1 \%$ Tau-squared $=0.3076$

\section{GSE15008 \\ GSE19945 \\ GSE25508 \\ GSE48414 \\ GSE63805 \\ GSE72526 \\ GSE74190 \\ GSE77380}

Random effects model

Pooled negative LR=0.57 ( 0.42 to 0.77$)$

Cochran- $\mathrm{Q}=55.97 ; \mathrm{df}=7$ ( $\mathrm{p}=0.0000)$

Inconsistency (I-square) $=87.5 \%$

Tau-squared $=0.1256$

Figure 7. Forest plots evaluating the pooled positive and negative likelihood ratios (LRs) of tissue miR-193a-5p. (A) Pooled positive LR of tissue miR-193a-5p. (B) Pooled negative LR tissue miR-193a-5p. LR, likelihood ratio; miR, microRNA. 


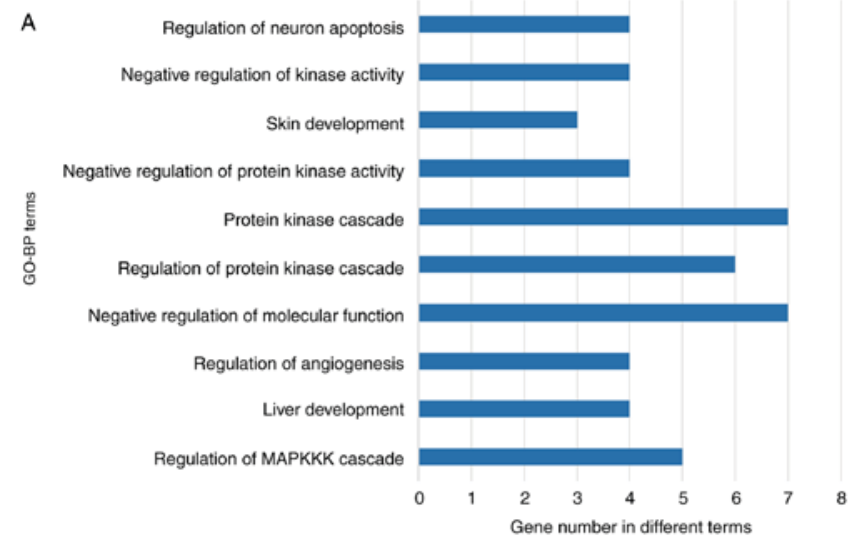

B

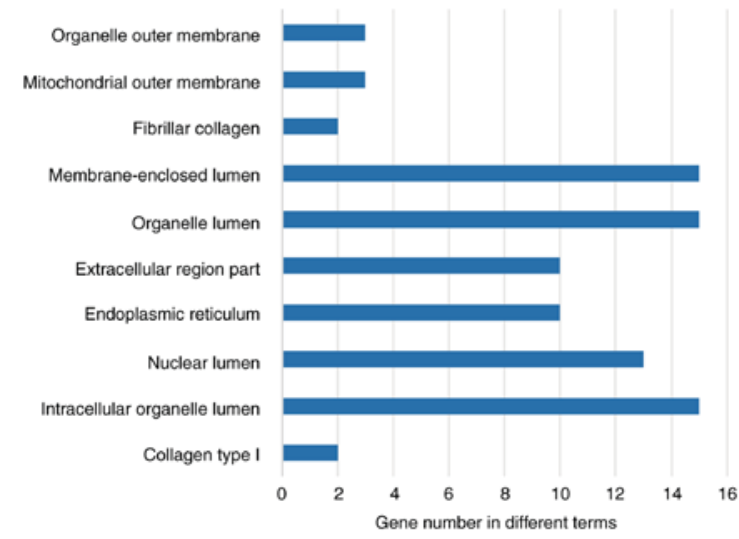

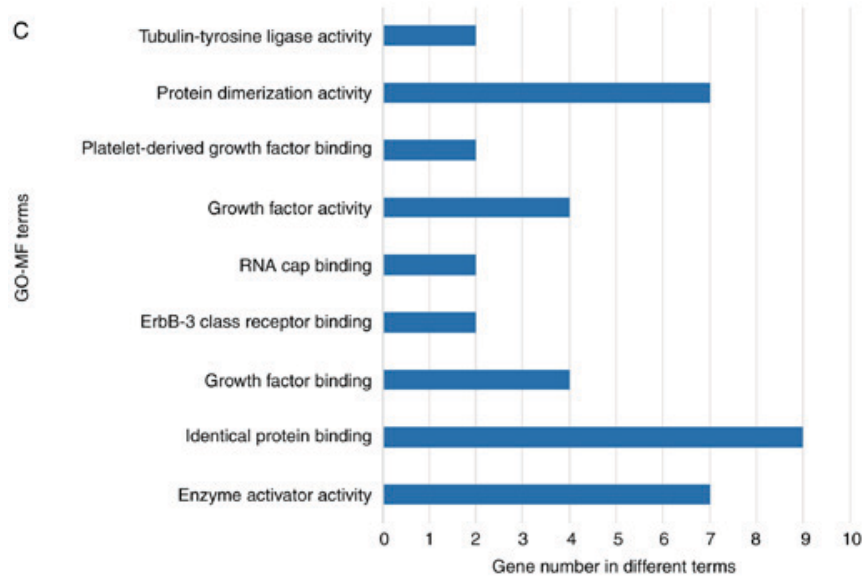

D

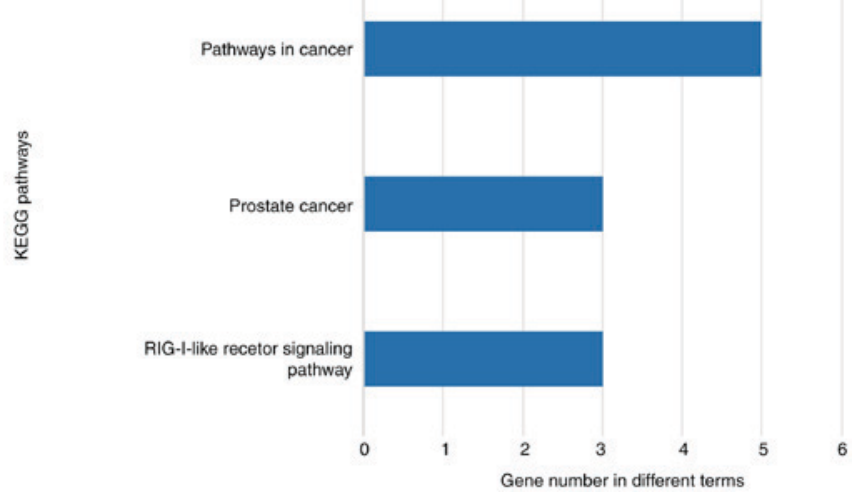

Figure 8. Significantly enriched GO and KEGG terms for the 81 overlapping genes. The X-axis represents the number of genes, and the Y-axis represents different terms. (A) The significantly enriched BP terms. (B) The significantly enriched CC terms. (C) The significantly enriched molecular function (MF) terms. (D) The significantly enriched KEGG terms. BP, biological process; CC, cellular component. GO, gene ontology; KEGG, Kyoto Encyclopedia of Genes and Genomes; BP, biological process; CC, cellular component; MF, molecular function.

in Fig. 3A, the combined sensitivity was 0.74 (95\% CI: 0.57 to $\left.0.86 ; \mathrm{I}^{2}=84.56 \% ; \mathrm{P}=0.00\right)$, while the specificity was 0.56 (95\% CI: 0.44 to $0.67 ; \mathrm{I}^{2}=68.08 \% ; \mathrm{P}=0.00$ ). Fig. $3 \mathrm{~B}$ shows that the pooled diagnostic odds ratio (OR) was 3.21 (95\% CI: 2.00 to 5.15). The pooled positive LR and negative LR were also calculated to evaluate the association between miR-193a-5p and lung cancer (Fig. 4A and B). The pooled positive LR was 1.58 (95\% CI: 1.35 to 1.85 ), while the negative LR was 0.57 (95\% CI: 0.47 to 0.70$)$.

Meta-analysis of the diagnostic value of tissue miR-193-5p. As shown in Fig. 5A, eight tissue datasets were pooled using a random-effects model, and the pooled SMD was -0.34 (95\% CI: -0.59 to $-0.08 ; \mathrm{I}^{2}=63.2 \% ; \mathrm{P}=0.008$ ). A Begg's funnel plot was constructed, and no publication bias was found, as the funnel plot was symmetrical (Fig. 5B). In addition, SROC curve analysis showed satisfactory diagnostic value of tissue miR-193-5p, with an AUC of 0.83 (95\% CI: 0.79 to 0.86) (Fig. 2B). The combined sensitivity and specificity was 0.65 (95\% CI: $0.43-0.83$ ) and 0.89 (95\% CI: 0.58 to 0.98 ), respectively (Fig. 6A). However, significant heterogeneity was found $\left(\mathrm{I}^{2}>50 \% ; \mathrm{P}<0.05\right)$. The combined diagnostic OR was 5.08 (95\% CI: 2.17 to 11.89), which was calculated using a random-effects model due to the heterogeneity (Fig. 6B). Moreover, the pooled positive LR and negative LR was 2.15 (95\% CI: 1.27 to 3.64 ) and 0.57 (95\% CI: 0.42 to 0.77$)$, respectively (Fig. 7A and B).
Identification of miR-193a-5p targets. A total of 12666 predicted target genes were obtained from miRWalk 2.0. Meanwhile, 94 validated target genes were collected from miRTarbase and Tarbase. Eighty-one overlapping genes were identified by comparing the predicted and validated target genes. The 81 overlapping genes are important miR-193a-5p target genes and were used for further bioinformatics analysis.

Bioinformatics analysis of the overlapping genes. GO, KEGG and PPI bioinformatics analyses were carried out for the overlapping genes (Table II). As shown in Fig. 8A, in biological process (BP), the top three enriched items were regulation of neuron apoptosis, negative regulation of kinase activity and skin development. In cellular component (CC), organelle outer membrane, mitochondrial outer membrane and fibrillar collagen were the top three enriched terms (Fig. 8B). For molecular function (MF), the target genes were mainly enriched in tubulin-tyrosine ligase activity, protein dimerization activity and platelet-derived growth factor binding (Fig. 8C). KEGG analysis showed that the significant terms associated with miR-193a-5p in lung cancer were pathway in cancer, prostate cancer and RIG-I-like receptor signaling pathway (Fig. 8D). By constructing a PPI network (Fig. 9), we identified 6 hub genes with a connection degree $>3$ (ERBB2, NCBP2, COL1A1, PCSK9, CSNK2A1, and UBTF). These 6 hub genes were the most densely connected areas in the network and were supported by additional evidence based 


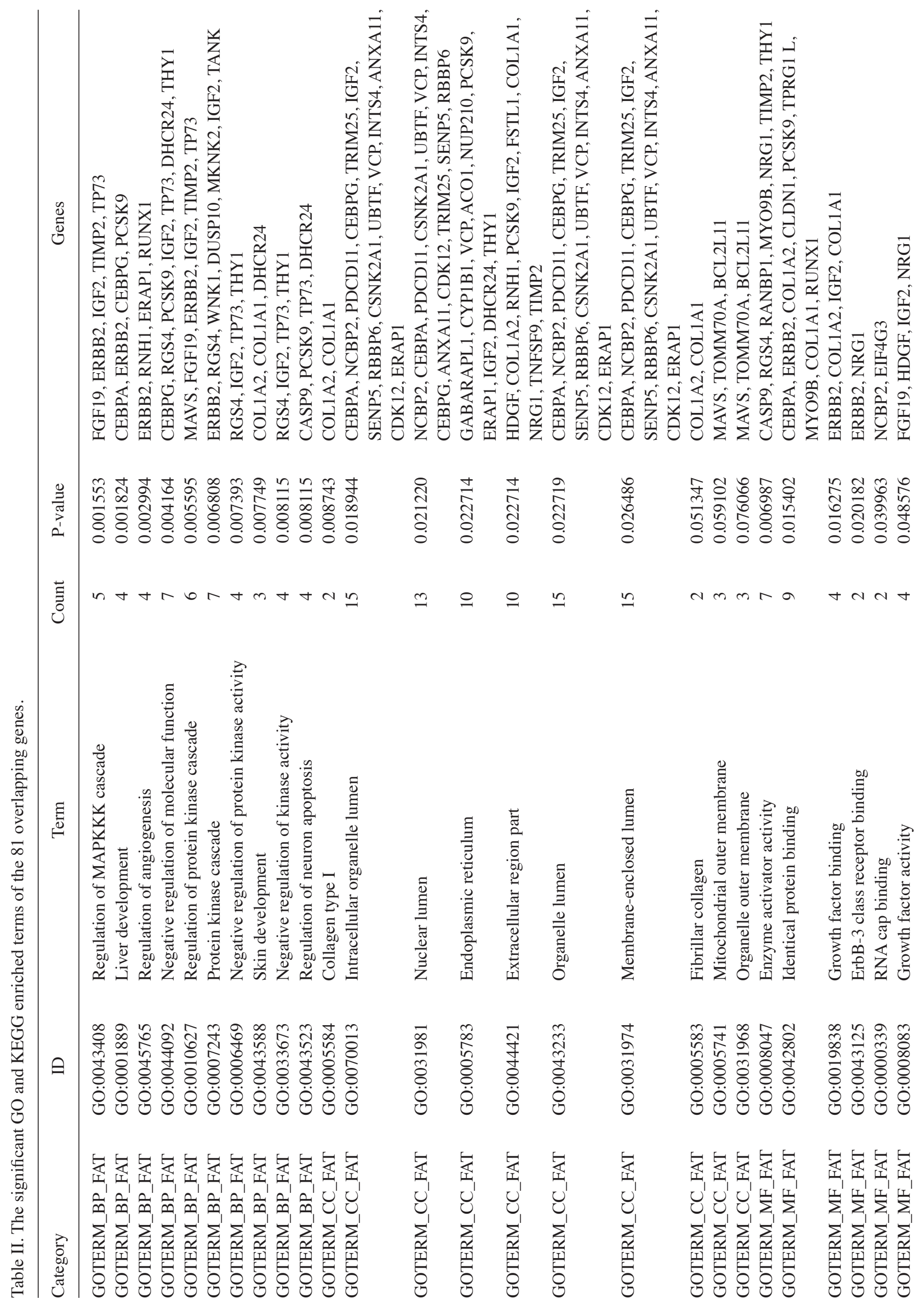


on known interactions. These genes were more likely to be functionally connected, thus showing great potential to be key target genes of miR-193a-5p in lung cancer.

Hub gene expression validation and clinical significance. The expression of the six hub genes (ERBB2, NCBP2, COL1A1, PCSK9, CSNK2A1, UBTF) is shown in scatter plots. ROC curves were also generated. We found that the expression of five of the hub genes (ERBB2, NCBP2, COL1A1, CSNK2A1, UBTF) were significantly upregulated in cancer. In addition, ROC curve analysis also showed that NCBP2, COL1A1, CSNK2A1 had satisfactory diagnostic value (Fig. 10). The AUC of ERBB2, NCBP2, COL1A1, CSNK2A1 and UBTF was $0.581,0.898,0.868,0.899$ and 0.723 , respectively. However, the expression of PCSK9 was significantly downregulated in cancer, and the ROC curve analysis showed that its AUC was 0.899 (Fig. 11).

Protein expression of the upregulated hub genes. Antibody staining was performed (Fig. 12) and among the five upregulated hub genes, ERBB2, NCBP2, COL1A1, CSNK2A1 and UBTF, we discovered that the antibody staining of NCBP2 and UBTF was high (Fig. 12B and E), while that of ERBB2, COL1A1 and CSNK2A1 (Fig. 12A, C and D) was moderate in pathological LUAD sections. In pathological LUSC sections, the antibody staining of NCBP2, CSNK2A1 and UBTF was high (Fig. 12G, I and J), while that of ERBB2 and COL1A1 was moderate (Fig. 12F and $\mathrm{H}$ ). The protein expression of ERBB2, NCBP2, COL1A1, CSNK2A1 and UBTF was upregulated in both LUAD and LUSC pathological sections. ERBB2 and COL1A1 were localized in the cytoplasm and cell membrane in both LUAD and LUSC pathological sections. CSNK2A1 and UBTF staining was predominantly nuclear in both LUAD and LUSC pathological sections. In LUAD sections, NCBP2 staining was both cytoplasmic/membranous and nuclear, while in LUSC sections, it was observed only in the nucleus.

Correlation between miR-193a-5p and hub genes. We analyzed a total of 1046 lung cancer samples from the TCGA database, including 533 LUAD and 513 LUSC samples. Among the five upregulated hub genes, we found that the expression of NCBP2 and CSNK2A1 was negatively correlated with that of miR-193a-5p $(\mathrm{P}<0.05)$. The correlation coefficient $r$ was -0.154 (CI: -0.214 to -0.092 ) and -0.156 (CI: -0.216 to -0.094$)$, respectively (Fig. 13). This finding further suggested that NCBP2 and CSNK2A1 are target genes of miR-193a-5p. However, there was no significant negative correlation between ERBB2, COL1A1 or UBTF and miR-193a-5p. Thus, based on our correlation analysis, we were unable to verify that ERBB2, COL1A1, and UBTF are miR-193a-5p target genes.

\section{Discussion}

In this study, we aimed to examine the diagnostic value of peripheral blood and tissue miR-193a-5p expression. We also attempted to elucidate the molecular regulatory mechanism underlying miR-193a-5p in lung cancer. We selected eligible microarray datasets and conducted a meta-analysis to explore the clinical diagnostic significance of miR-193a-5p. We then used bioinformatics analysis to explore the potential molecular 


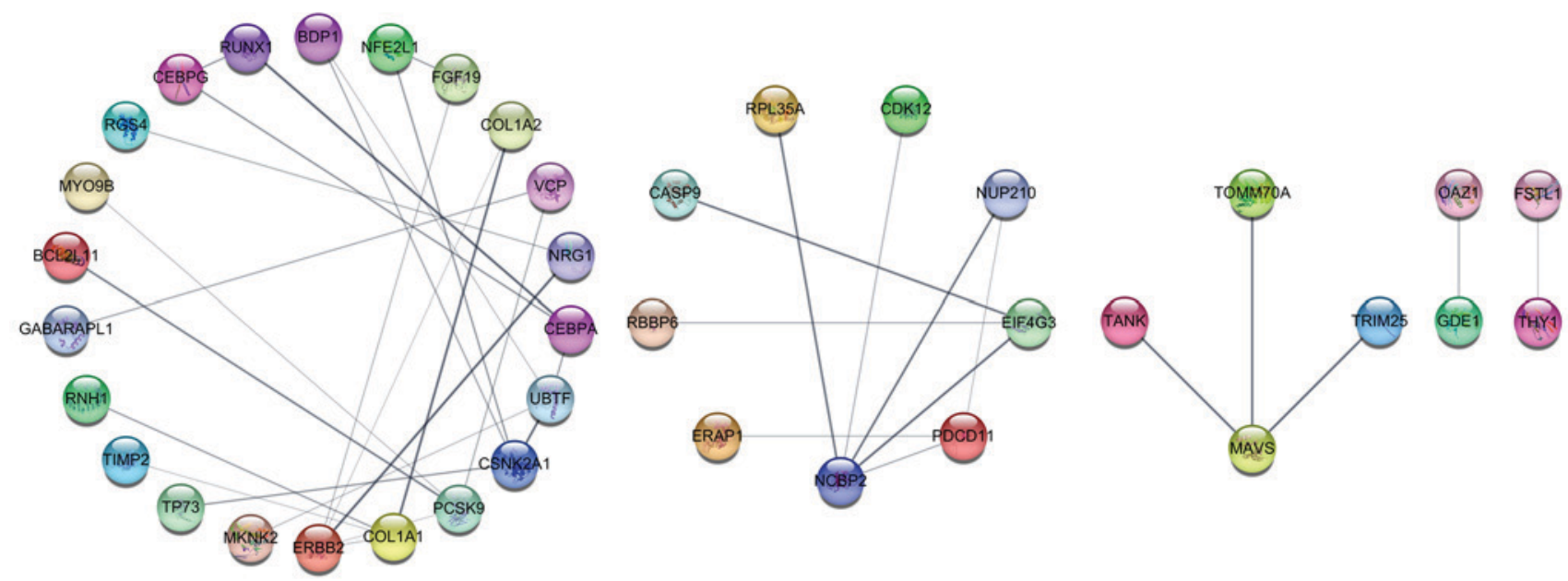

Figure 9. Protein-protein interaction network of the overlapping genes. Each node represents a protein. Filled nodes indicate that 3D structure of the protein is known or predicted. Empty nodes indicate that the 3D structure of the protein has not been determined. The edges among the nodes represent the protein associations. The edge thickness indicates the confidence level. PPI, protein-protein interaction.
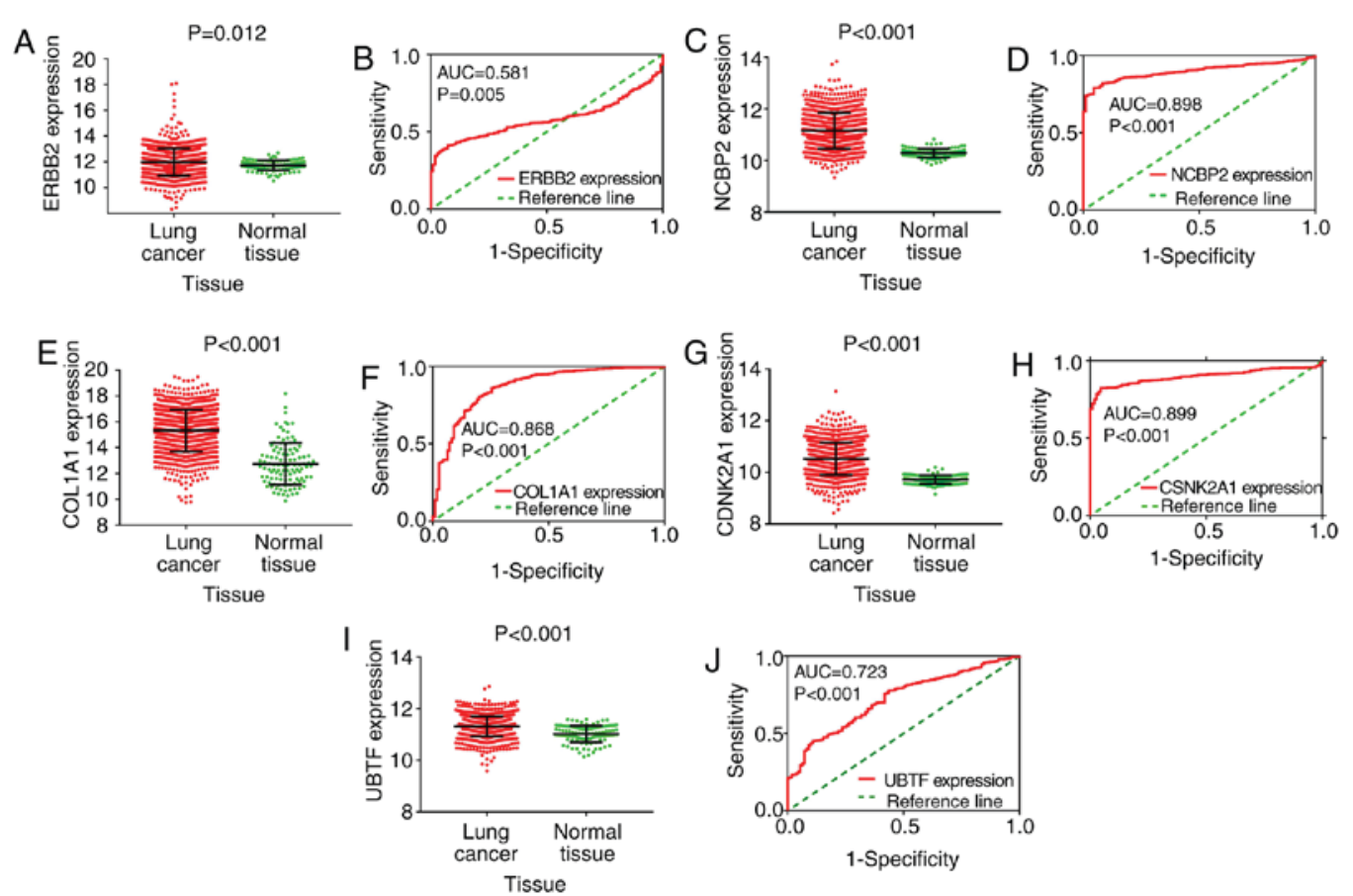

Figure 10. The expression scatter plots and ROC curves of the five upregulated hub genes. (A) The expression of ERBB2 in lung cancer and normal tissues. (B) The ROC curve of ERBB2 to assess the diagnostic value. (C) The expression of NCBP2 in lung cancer and normal tissues. (D) The ROC curve of NCBP2 to assess the diagnostic value. (E) The expression of COL1A1 in lung cancer and normal tissues. (F) The ROC curve of COL1A1 to assess the diagnostic value. (G) The expression of CSKN2A1 in lung cancer and normal tissues. (H) The ROC curve of CSKN2A1 to assess the diagnostic value. (I) The expression of UBTF in lung cancer and normal tissues. (J) The ROC curve of UBTF in lung cancer and normal tissues. ROC, receiver operating characteristic; AUC, area under the curve.
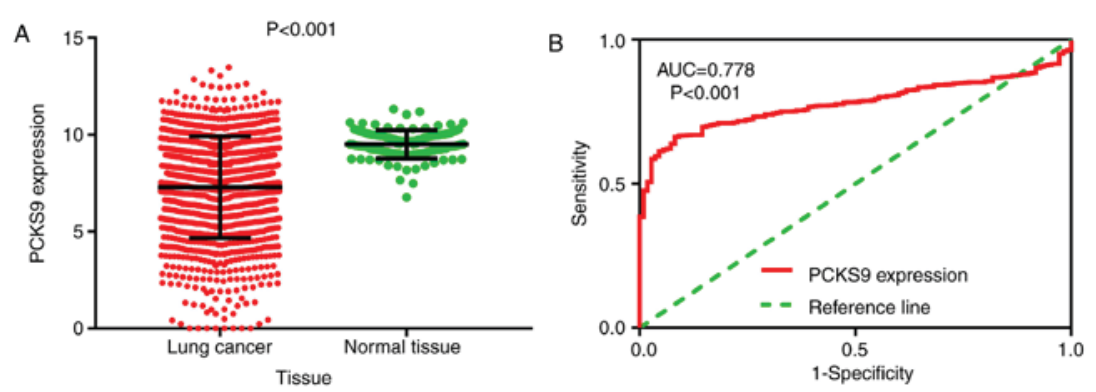

Figure 11. The expression scatter plots and ROC curve of the downregulated hub gene. (A) The expression of PCKS9 in lung cancer and normal tissues. (B) The ROC curve of PCKS9 in lung cancer and normal tissues. ROC, receiver operating characteristic; AUC, area under the curve. 


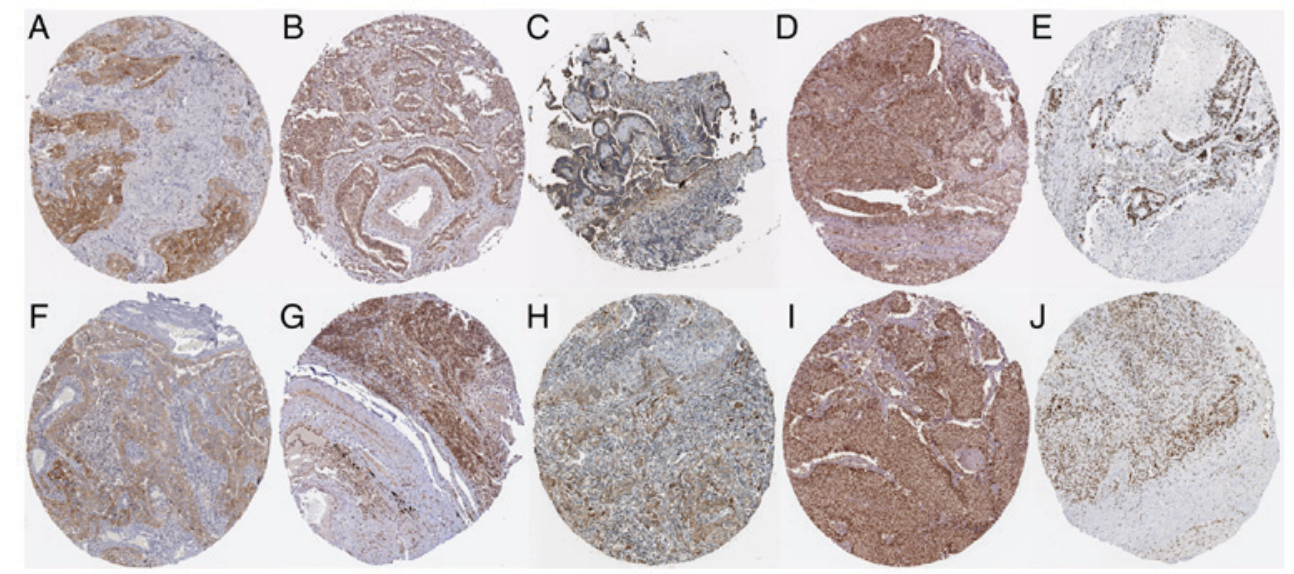

Figure 12. The protein expression of the hub genes based on The Human Protein Atlas database (https://www.proteinatlas.org/). Brown staining indicates protein expression. Darker staining indicates higher protein expression. (A) Medium staining of ERBB2 in LUAD (stained with the antibody HPA001383). (B) High staining of NCBP2 in LUAD (stained with the antibody HPA044850). (C) Medium staining of COL1A1 in LUAD (stained with the antibody HPA011795). (D) Medium staining of CSNK2A1 in LUAD (stained with the antibody CAB069395). (E) High staining of UBTF in LUAD (stained with the antibody CAB004611). (F) Medium staining of ERBB2 in LUSC (stained with the antibody HPA001383). (G) High staining of NCBP2 in LUSC (stained with the antibody HPA044850). (H) Medium staining of COL1A1 in LUSC (stained with the antibody HPA011795). (I) High staining of CSNK2A1 in LUSC (stained with the antibody CAB069395). (J) High staining of UBTF in LUSC (stained with the antibody CAB004611). Magnification, x40. LUAD, lung adenocarcinoma; LUSC, lung squamous cell carcinoma.

A

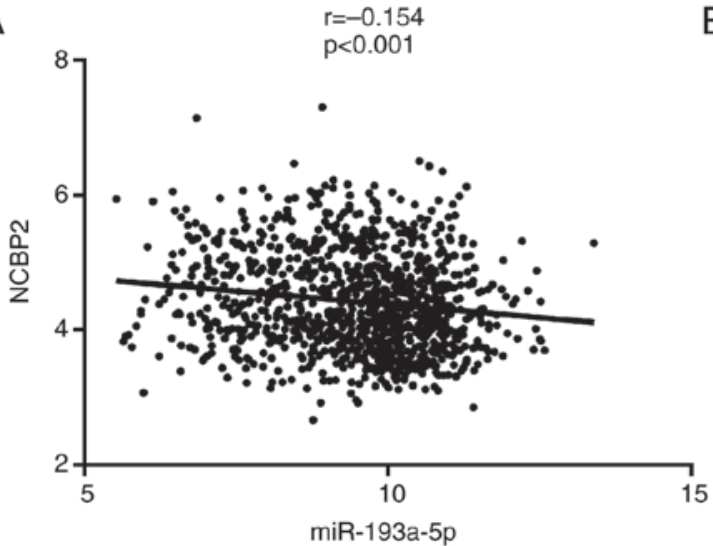

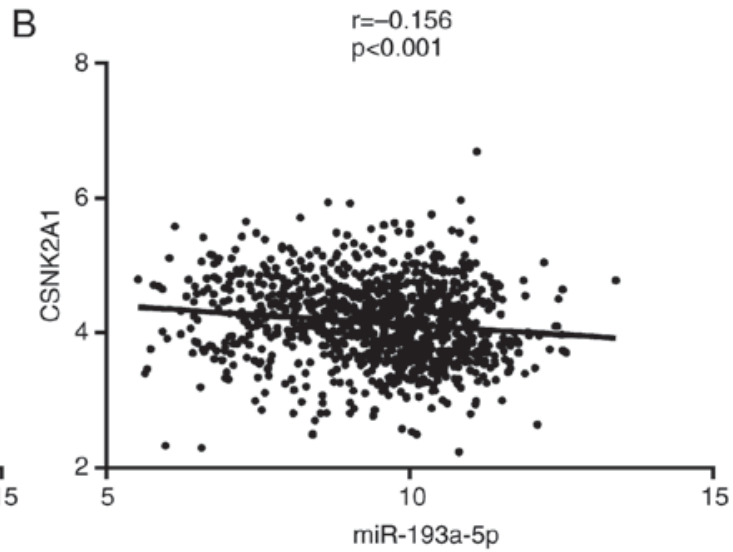

Figure 13. The correlation between miR-193a-5p and hub genes. Each plot represents a lung cancer sample. The X-axis represents the expression of miR-193a-5p. The Y-axis represents the expression of hub genes. (A) miR-193a-5p is negatively correlated with NCBP2. (B) miR-193a-5p is negatively correlated with CSNK2A1. miR, microRNA.

mechanism involved. We compared predicted and validated target genes of miR-193a-5p and identified the overlapping genes. GO, KEGG and PPI network analyses were further performed for the overlapping genes. This study therefore provides a foundation for future research on miR-193a-5p.

Over the past few decades, the identification of diagnostic biomarkers in lung cancer has been an important research focus. Some classic and useful biomarkers such as TP53 (50,51), neuron-specific enolase (NSE) $(52,53)$, carcinoembryonic antigen (CEA) $(54,55)$, and the cytokeratin 19 fragment (CYFRA21-1) $(56,57)$ have been identified and applied in clinical diagnosis. Nevertheless, there is still a need to identify diagnostic markers of lung cancer. Increasingly, lncRNAs and miRNAs have been found to act as diagnostic markers in lung cancer (58-62). The combination of multiple diagnostic biomarkers would greatly improve the sensitivity and specificity of lung cancer diagnosis $(56,63,64)$. Thus, each finding is likely to contribute to the future clinical diagnosis of lung cancer. No previous studies have elucidated the diagnostic value of miR-193a-5p through a comprehensive meta-analysis. In this study, we used a microarray meta-analysis to explore the diagnostic value of miR-193a-5p in lung cancer. We found that the expression of peripheral blood miR-193a-5p was significantly higher in lung cancer samples than in normal samples. The pooled AUC was 0.67, with a sensitivity of 0.74 and specificity of 0.56 . The pooled diagnostic OR was 3.21, the positive likelihood ratio was 1.58 and the negative likelihood ratio was 0.57 . Thus, peripheral blood miR-193a-5p displayed moderate diagnostic value. It may be useful to combine peripheral blood miR-193a-5p with other diagnostic markers to improve its clinical diagnostic efficacy. Surprisingly, in tissue samples, the expression of miR-193a-5p in lung cancer tissue was evidently reduced compared with normal tissue. The pooled AUC was 0.83 , with a sensitivity of 0.65 and specificity of 0.89 . The diagnostic OR was 5.08 , the positive likelihood ratio was 2.15 , and the negative likelihood 
ratio was 0.57 . Thus, tissue miR-193a-5p expression exhibited satisfactory performance in diagnosing lung cancer and might be a promising clinical diagnostic biomarker. Interestingly, the expression of peripheral blood miR-193a-5p was not consistent with the expression observed in lung cancer tissue samples. The reasons for this discrepancy between peripheral blood and tissue miRNA expression remain unclear. The origin of peripheral blood miRNAs remains controversial. Some researchers have suggested that miRNAs are secreted through microvesicles/exosomes, and some miRNAs are expressed at a higher level in microvesicles than inside tumor cells (65-67). In another study, Pigati et al (68) found that miRNAs were selectively released from malignant cells and that the level of miRNAs released did not necessarily reflect the original abundance of miRNAs in cells. In Hu's study, it was suggested that the clinical role of serum miRNAs was independent from that in tissue samples (69). These findings may indicate why the expression profiles of miR-193a-5p were opposite in peripheral blood and tissue specimens in our study. Further studies are needed to determine the exact mechanism that causes the difference in expression. Still, peripheral blood and tissue miR-193a-5p could facilitate the diagnosis of lung cancer to some extent.

Since miR-193a-5p exerts its regulatory effects by specifically targeting certain genes, we identified potential miR-193a-5p target genes and further uncovered the underlying regulatory pathways. We found that the top enriched GO terms in BP, CC and MF were regulation of neuron apoptosis, organelle outer membrane and tubulin-tyrosine ligase activity, respectively. Mitochondria are important organelles in most eukaryotes. Mitochondrial outer membrane permeabilization has been reported to be involved in cancer and may be a promising therapeutic target $(70,71)$. Therefore, miR-193a-5p might also participate in lung cancer through a similar mechanism. Recently, widespread loss of tubulin tyrosine ligase has been found during tumor growth, suggesting that tubulin tyrosine ligase activity might be involved in the regulation of tumor cells (72). Tubulin tyrosine ligase activity may be associated with miR-193a-5p, which might exert effects in lung cancer. However, more studies are needed to confirm this. In our KEGG analysis, the terms pathways in cancer, prostate cancer and RIG-I-like receptor signaling pathway were determined to be important. However, no studies have yet determined the relationship between miR-193a-5p and these pathways. Thus, more studies are urgently required. Through PPI network construction, six hub genes were identified (ERBB2, NCBP2, COL1A1, PCSK9, CSNK2A1, UBTF). By analyzing TCGA data, we discovered that among the six hub genes, five (ERBB2, NCBP2, COL1A1, CSNK2A1, UBTF) were significantly upregulated in lung cancer tissue. Since the expression of miR-193a-5p in lung cancer tissue was downregulated, the five upregulated hub genes (ERBB2, NCBP2, COL1A1, CSNK2A1, UBTF) are likely to be target genes of miR-193a-5p in lung cancer. However, more studies are needed to investigate the relationship between the significantly downregulated hub gene, PCSK9, and miR-193a-5p in lung cancer. Interestingly, we further verified that the protein expression of ERBB2, NCBP2, COL1A1, CSNK2A1 and UBTF was also upregulated according to antibody staining in LUAD and LUSC pathological sections. These results further demonstrated the upregulation of ERBB2, NCBP2, COL1A1, CSNK2A1 and UBTF in lung cancer, indicating that they are likely to be targets of miR-193a-5p. Of the five upregulated hub genes, NCBP2 and CSNK2A1 were found to be negatively correlated with miR-193a-5p. Consequently, we focused on NCBP2 and CSNK2A1 in the detailed discussion below.

NCBP2 (nuclear cap binding protein subunit 2) is also known as $\mathrm{CBC} 2$. Its protein product is a component of the nuclear cap-binding protein complex. NCBP2 has been reported as a key target gene in ovarian carcinoma (73). However, we did not find any studies on NCBP2 and lung cancer. In our study, we found that the protein expression of NCBP2 was increased in both LUAD and LUSC samples. In addition, miR-193a-5p was found to be negatively correlated with NCBP2 ( $\mathrm{r}=-0.154)$. These findings provided more evidence suggesting that NCBP2 may be a target of miR-193a-5p in lung cancer. Nevertheless, more relevant studies are required to further validate this hypothesis.

CSNK2A1 (casein kinase 2 alpha 1), also known as CKII, is a serine/threonine protein kinase that participates in various cellular processes, including the cell cycle, apoptosis, and circadian rhythm. Over the past few years, CSNK2A1 has been found to play a significant role in the survival of cancer patients, suggesting that it may be a promising therapeutic target (74-76). For example, in Bae JS's study, CSNK2A1 was found to participate in the progression of breast carcinoma and to indicate poorer patient survival (77). In addition, Rabjerg et al (78) identified CSNK2A1 as a promising novel prognostic biomarker in clear cell renal carcinoma. Furthermore, CSNK2A1 has also been found to be involved in ovarian cancer $(79)$, oral cancer $(80)$, prostate cancer $(81,82)$ and pancreatic cancer (83). A CK2 inhibitor has been implicated in the apoptosis, migration, and metastasis of lung cancer cells (84-87). Increased protein expression of CSNK2A1 was observed in both LUAD and LUSC samples. We also observed a negative correlation between miR-193a-5p and CSNK2A1 according to an analysis of TCGA data $(r=-0.156)$. Thus, CSNK2A1 could be a promising therapeutic target in lung cancer. Still, further experimental studies are needed.

In conclusion, in this study we discovered that peripheral blood and tissue miR-193a-5p could be a promising diagnostic biomarker for the clinical diagnosis of lung cancer. Several pathways regulated by miR-193a-5p and its targets, including pathways in cancer, prostate cancer and the RIG-I-like receptor signaling pathway, might be important in lung cancer. In addition, six hub genes, ERBB2, COL1A1, PCSK9, UBTF, and particularly NCBP2 and CSNK2A1, were identified as key target genes of miR-193a-5p. However, there were some limitations in this study. The analysis was based on online databases, and we only performed bioinformatics analyses. More experiments are needed to validate the findings. Luciferase assays would be a powerful method to validate the findings in the current study. Clinicall, this study could offer possible insights into lung cancer diagnosis and provide a basis for future research on the molecular mechanisms involved.

\section{Acknowledgements}

Not applicable. 


\section{Funding}

The present study was supported the Fund of the Natural Science Foundation of Guangxi, China (grant no. 2016GXNSFAA380255) and Future Academic Star of Guangxi Medical University (grant no. WLXSZX17042). The funders were not involved in the study design, data collection and analysis, the decision to publish or preparation of the manuscript.

\section{Availability of data and materials}

All the data and materials used in the current study are freely accessible in GEO (https://www.ncbi.nlm.nih.gov/geo/), TCGA (https://cancergenome.nih.gov/), miRWalk 2.0 (http:// zmf.umm.uni-heidelberg.de/apps/zmf/mirwalk2/), Tarbase (http://diana.imis.athena-innovation.gr/DianaTools/index. php?r=tarbase/index), MitarBase (http://mirtarbase.mbc.nctu. edu.tw/php/index.php), DAVID (https://david.ncifcrf.gov/), STRING (https://string-db.org/) and the Human Protein Atlas databases (https://www.proteinatlas.org/).

\section{Authors' contributions}

ZYL and GC designed the study and revised the manuscript. ZCX, RXT, XG, QNX, and JYL contributed to the collection and analysis of the data, as well as the writing of the manuscript.

\section{Ethics approval and consent to participate}

Not applicable.

\section{Consent for publication}

Not applicable.

\section{Competing interests}

The authors declare that they have no competing interests.

\section{References}

1. Siegel RL, Miller KD and Jemal A: Cancer Statistics, 2017. CA A Cancer J Clin 67: 7-30, 2017.

2. Lu C, Shan Z, Hong J and Yang L: MicroRNA-92a promotes epithelial-mesenchymal transition through activation of PTEN/PI3K/AKT signaling pathway in non-small cell lung cancer metastasis. Int J Oncol 51: 235-244, 2017.

3. Armas-Lopez L, Piña-Sánchez P, Arrieta O, de Alba EG, Ortiz-Quintero B, Santillán-Doherty P, Christiani DC, Zúñiga J and Ávila-Moreno F: Epigenomic study identifies a novel mesenchyme homeobox2-GLI1 transcription axis involved in cancer drug resistance, overall survival and therapy prognosis in lung cancer patients. Oncotarget 8: 67056-67081, 2017.

4. Bai M, Li W, Yu N, Zhang H, Long F and Zeng A: The crosstalk between $\beta$-catenin signaling and type I, type II and type III interferons in lung cancer cells. Am J Transl Res 9: 2788-2797, 2017.

5. Hu T and Lu YR: BCYRN1, a c-MYC-activated long non-coding RNA, regulates cell metastasis of non-small-cell lung cancer. Cancer Cell Int 15: 36, 2015.

6. Pang L, Han S, Jiao Y, Jiang S, He X and Li P: Bu Fei Decoction attenuates the tumor associated macrophage stimulated proliferation, migration, invasion and immunosuppression of non-small cell lung cancer, partially via IL-10 and PD-L1 regulation. Int J Oncol 51: 25-38, 2017.
7. Bartel DP: MicroRNAs: Target recognition and regulatory functions. Cell 136: 215-233, 2009.

8. Romero-Cordoba SL, Salido-Guadarrama I Rodriguez-Dorantes $M$ and Hidalgo-Miranda A: miRNA biogenesis: Biological impact in the development of cancer. Cancer Biol Ther 15: 1444-1455, 2014

9. Naidu S, Magee P and Garofalo M: miRNA-based therapeutic intervention of cancer. J Hematol Oncol 8: 68, 2015.

10. Ganju A, Khan S, Hafeez BB, Behrman SW, Yallapu MM, Chauhan SC and Jaggi M: miRNA nanotherapeutics for cancer. Drug Discov Today 22: 424-432, 2017.

11. Mishra S, Yadav T and Rani V: Exploring miRNA based approaches in cancer diagnostics and therapeutics. Crit Rev Oncol Hematol 98: 12-23, 2016.

12. Zhao C, Lu F, Chen H, Zhao F, Zhu Z, Zhao X and Chen H: Clinical significance of circulating miRNA detection in lung cancer. Med Oncol 33: 41, 2016.

13. Jiang $\mathrm{C}, \mathrm{Hu} \mathrm{X}$, Alattar $\mathrm{M}$ and Zhao $\mathrm{H}$ : miRNA expression profiles associated with diagnosis and prognosis in lung cancer. Expert Rev Anticancer Ther 14: 453-461, 2014.

14. Lin CH, Tsai CH, Yeh CT, Liang JL, Hung WC, Lin FC, Chang WL, Li HY, Yao YC, Hsu TI, et al: miR-193a-5p/ERBB2 act as concurrent chemoradiation therapy response indicator of esophageal squamous cell carcinoma. Oncotarget 7: 39680-39693, 2016.

15. Zhou J, Duan H, Xie Y, Ning Y, Zhang X, Hui N, Wang C, Zhang J and Zhou J: miR-193a-5p targets the coding region of AP-2a mRNA and induces cisplatin resistance in bladder cancers. J Cancer 7: 1740-1746, 2016.

16. Jacques C, Calleja LR, Baud'huin M, Quillard T, Heymann D, Lamoureux F and Ory B: miRNA-193a-5p repression of p73 controls Cisplatin chemoresistance in primary bone tumors. Oncotarget 7: 54503-54514, 2016.

17. Pu Y, Zhao F, Cai W, Meng X, Li Y and Cai S: miR-193a-3p and miR-193a-5p suppress the metastasis of human osteosarcoma cells by down-regulating Rab27B and SRR, respectively. Clin Exp Metastasis 33: 359-372, 2016.

18. Zhang P, Ji DB, Han HB, Shi YF, Du CZ and Gu J: Downregulation of miR-193a-5p correlates with lymph node metastasis and poor prognosis in colorectal cancer. World J Gastroenterol 20: 12241-12248, 2014.

19. Yang Y, Zhou L, Lu L, Wang L, Li X, Jiang P, Chan LK, Zhang T, Yu J, Kwong J, et al: A novel miR-193a-5p-YY1-APC regulatory axis in human endometrioid endometrial adenocarcinoma. Oncogene 32: 3432-3442, 2013.

20. Toren P and Zoubeidi A: Targeting the PI3K/Akt pathway in prostate cancer: Challenges and opportunities (review). Int J Oncol 45: 1793-1801, 2014.

21. Georgi B, Korzeniewski N, Hadaschik B, Grüllich C, Roth W, Sültmann H, Pahernik S, Hohenfellner $M$ and Duensing S: Evolving therapeutic concepts in prostate cancer based on genome-wide analyses (review). Int J Oncol 45: 1337-1344, 2014.

22. Xie Y, Naizabekov S, Chen Z and Tokay T: Power of PTEN/AKT: Molecular switch between tumor suppressors and oncogenes. Oncol Lett 12: 375-378, 2016.

23. Steelman LS, Martelli AM, Cocco L, Libra M, Nicoletti F, Abrams SL and McCubrey JA: The therapeutic potential of mTOR inhibitors in breast cancer. Br J Clin Pharmacol 82: 1189-1212, 2016.

24. Nicoletti F, Fagone P, Meroni P, McCubrey J and Bendtzen K: mTOR as a multifunctional therapeutic target in HIV infection. Drug Discov Today 16: 715-721, 2011.

25. Yu T, Li J, Yan M, Liu L, Lin H, Zhao F, Sun L, Zhang Y, Cui Y, Zhang F, et al: MicroRNA-193a-3p and -5p suppress the metastasis of human non-small-cell lung cancer by downregulating the ERBB4/PIK3R3/mTOR/S6K2 signaling pathway. Oncogene 34: 413-423, 2015.

26. Chen J, Gao S, Wang C, Wang Z, Zhang H, Huang K, Zhou B, $\mathrm{Li} \mathrm{H}, \mathrm{Yu} \mathrm{Z}, \mathrm{Wu} \mathrm{J}$ and Chen C: Pathologically decreased expression of miR-193a contributes to metastasis by targeting WT1-E-cadherin axis in non-small cell lung cancers. J Exp Clin Cancer Res 35: 173, 2016.

27. Dweep H and Gretz N: miRWalk2.0: A comprehensive atlas of microRNA-target interactions. Nat Methods 12: 697, 2015.

28. Huang da W, Sherman BT and Lempicki RA: Systematic and integrative analysis of large gene lists using DAVID bioinformatics resources. Nat Protoc 4: 44-57, 2009.

29. Huang da W, Sherman BT and Lempicki RA: Bioinformatics enrichment tools: Paths toward the comprehensive functional analysis of large gene lists. Nucleic Acids Res 37: 1-13, 2009. 
30. Szklarczyk D, Franceschini A, Wyder S, Forslund K, Heller D, Huerta-Cepas J, Simonovic M, Roth A, Santos A, Tsafou KP, et al: STRING v10: Protein-protein interaction networks, integrated over the tree of life. Nucleic Acids Res 43: D447-D452, 2015.

31. Tomczak K, Czerwinska P and Wiznerowicz M: The cancer genome atlas (TCGA): An immeasurable source of knowledge. Contemp oncol (Pozn) 19: A68-A77, 2015.

32. Uhlén M, Fagerberg L, Hallström BM, Lindskog C, Oksvold P, Mardinoglu A, Sivertsson Å, Kampf C, Sjöstedt E, Asplund A, et al: Proteomics. Tissue-based map of the human proteome. Science 347: 1260419, 2015.

33. Thul PJ, Akesson L, Wiking M, Mahdessian D, Geladaki A, Ait Blal H, Alm T, Asplund A, Björk L, Breckels LM, et al: A subcellular map of the human proteome. Science 356: eaal3321, 2017.

34. Uhlen M, Zhang C, Lee S, Sjöstedt E, Fagerberg L, Bidkhori G, Benfeitas R, Arif M, Liu Z, Edfors F, et al: A pathology atlas of the human cancer transcriptome. Science 357: eaan2507, 2017.

35. Keller A, Leidinger P, Borries A, Wendschlag A, Wucherpfennig F, Scheffler M, Huwer H, Lenhof HP and Meese E: miRNAs in lung cancer - studying complex fingerprints in patient's blood cells by microarray experiments. BMC cancer 9: 353, 2009.

36. Patnaik SK, Yendamuri S, Kannisto E, Kucharczuk JC, Singhal S and Vachani A: MicroRNA expression profiles of whole blood in lung adenocarcinoma. PloS One 7: e46045, 2012

37. Keller A, Leidinger P, Bauer A, Elsharawy A, Haas J, Backes C, Wendschlag A, Giese N, Tjaden C, Ott K, et al: Toward the bloodborne miRNome of human diseases. Nat Methods 8: 841-843, 2011.

38. Patnaik SK, Kannisto ED, Mallick R, Vachani A and Yendamuri S: Whole blood microRNA expression may not be useful for screening non-small cell lung cancer. PloS One 12: e0181926, 2017.

39. Keller A, Leidinger P, Vogel B, Backes C, ElSharawy A, Galata V, Mueller SC, Marquart S, Schrauder MG, Strick R, et al: miRNAs can be generally associated with human pathologies as exemplified for miR-144. BMC Med 12: 224, 2014.

40. https://www.ncbi.nlm.nih.gov/geo/query/acc.cgi?acc=GSE46729. Accessed January 8, 2017.

41. Leidinger P, Galata V, Backes C, Stähler C, Rheinheimer S, Huwer H, Meese E and Keller A: Longitudinal study on circulating miRNAs in patients after lung cancer resection. Oncotarget 6: 16674-16685, 2015.

42. Tan X, Qin W, Zhang L, Hang J, Li B, Zhang C, Wan J, Zhou F, Shao K, Sun Y, et al: A 5-microRNA signature for lung squamous cell carcinoma diagnosis and hsa-miR-31 for prognosis. Clin Cancer Res 17: 6802-6811, 2011.

43. Nymark P, Guled M, Borze I, Faisal A, Lahti L, Salmenkivi K, Kettunen E, Anttila S and Knuutila S: Integrative analysis of microRNA, mRNA and aCGH data reveals asbestos- and histology-related changes in lung cancer. Genes Chromosomes Cancer 50: 585-597, 2011.

44. https://www.ncbi.nlm.nih.gov/geo/query/acc.cgi?acc=GSE19945. Accessed January 8, 2017.

45. Bjaanaes MM, Halvorsen AR, Solberg S, Jørgensen L, Dragani TA, Galvan A, Colombo F, Anderlini M, Pastorino U, Kure E, et al: Unique microRNA-profiles in EGFR-mutated lung adenocarcinomas. Int J Cancer 135: 1812-1821, 2014.

46. Robles AI, Arai E, Mathé EA, Okayama H, Schetter AJ, Brown D, Petersen D, Bowman ED, Noro R, Welsh JA, et al: An integrated prognostic classifier for stage I lung adenocarcinoma based on mRNA, microRNA, and DNA methylation Biomarkers. J Thorac Oncol 10: 1037-1048, 2015.

47. Gasparini P, Cascione L, Landi L, Carasi S, Lovat F, Tibaldi C, Alì G, D'Incecco A, Minuti G, Chella A, et al: microRNA classifiers are powerful diagnostic/prognostic tools in ALK-, EGFR-, and KRAS-driven lung cancers. Proc Natl Acad Sci USA 112: 14924-14929, 2015.

48. https://www.ncbi.nlm.nih.gov/geo/query/acc.cgi?acc=GSE74190. Accessed January 8, 2017

49. Yoshimoto T1, Motoi N, Yamamoto N, Nagano H, Ushijima M, Matsuura M, Okumura S, Yamaguchi T, Fukayama M and Ishikawa Y: Pulmonary carcinoids and low-grade gastrointestinal neuroendocrine tumors show common microRNA expression profiles, different from adenocarcinomas and small cell carcinomas. Neuroendocrinology 106: 47-57, 2018

50. Halvorsen AR, Silwal-Pandit L, Meza-Zepeda LA, Vodak D, Vu P, Sagerup C, Hovig E, Myklebost O, Børresen-Dale AL, Brustugun OT and Helland A: TP53 mutation spectrum in smokers and never smoking lung cancer patients. Front Genet 7: 85, 2016.
51. Mogi A and Kuwano H: TP53 mutations in nonsmall cell lung cancer. J Biomed Biotechnol 2011: 583929, 2011.

52. Huang L, Zhou JG, Yao WX, Tian X, Lv SP, Zhang TY, Jin SH, Bai YJ and Ma H: Systematic review and meta-analysis of the efficacy of serum neuron-specific enolase for early small cell lung cancer screening. Oncotarget 8: 64358-64372, 2017.

53. Isgro MA, Bottoni P and Scatena R: Neuron-specific enolase as a biomarker: Biochemical and clinical aspects. Adv Exp Med Biol 867: 125-143, 2015.

54. Zou Y, Wang L, Zhao C, Hu Y, Xu S, Ying K, Wang P and Chen X: CEA, SCC and NSE levels in exhaled breath condensate-possible markers for early detection of lung cancer. J Breath Res 7: 047101, 2013.

55. Grunnet $M$ and Sorensen JB: Carcinoembryonic antigen (CEA) as tumor marker in lung cancer. Lung Cancer 76: $138-143,2012$

56. Wang B, He YJ, Tian YX, Yang RN, Zhu YR and Qiu H: Clinical utility of haptoglobin in combination with CEA, NSE and CYFRA21-1 for diagnosis of lung cancer. Asian Pac J Cancer Prev 15: 9611-9614, 2014.

57. Okamura K, Takayama K, Izumi M, Harada T, Furuyama K and Nakanishi Y: Diagnostic value of CEA and CYFRA 21-1 tumor markers in primary lung cancer. Lung Cancer 80: 45-49, 2013.

58. Li N, Wang $\mathrm{Y}$, Liu $\mathrm{X}$, Luo $\mathrm{P}$, Jing $\mathrm{W}$, Zhu $\mathrm{M}$ and Tu J: Identification of circulating long noncoding RNA HOTAIR as a novel biomarker for diagnosis and monitoring of non-small cell lung cancer. Technol Cancer Res Treat: Jan 1, 2017 (Epub ahead of print).

59. Zhou Q, Huang SX, Zhang F, Li SJ, Liu C, Xi YY, Wang L, Wang X, He QQ, Sun CC and Li DJ: MicroRNAs: A novel potential biomarker for diagnosis and therapy in patients with non-small cell lung cancer. Cell Prolif 50, 2017 doi: $10.1111 /$ cpr.12394

60. Inamura K: Diagnostic and therapeutic potential of MicroRNAs in lung cancer. Cancers 9: E49, 2017.

61. Ricciuti B, Mencaroni C, Paglialunga L, Paciullo F, Crinò L, Chiari R and Metro G: Long noncoding RNAs: New insights into non-small cell lung cancer biology, diagnosis and therapy. Med Oncol 33: 18, 2016.

62. Chen J, Wang R, Zhang K and Chen LB: Long non-coding RNAs in non-small cell lung cancer as biomarkers and therapeutic targets. J Cell Mol Med 18: 2425-2436, 2014.

63. Pan YW, Zhou ZG, Wang M, Dong JQ, Du KP, Li S, Liu YL, Lv PJ and Gao JB: Combination of IL-6, IL-10 and MCP-1 with traditional serum tumor markers in lung cancer diagnosis and prognosis. Genet Mol Res 15: 2016 doi: 10.4238/gmr15048949.

64. Wang WJ, Tao Z, Gu W and Sun LH: Clinical observations on the association between diagnosis of lung cancer and serum tumor markers in combination. Asian Pac J Cancer Prev 14: 4369-4371, 2013.

65. Mitchell PS, Parkin RK, Kroh EM, Fritz BR, Wyman SK, Pogosova-Agadjanyan EL, Peterson A, Noteboom J, O'Briant KC, Allen A, et al: Circulating microRNAs as stable blood-based markers for cancer detection. Proc Natl Acad Sci USA 105: 10513-10518, 2008.

66. Skog J, Wurdinger T, van Rijn S, Meijer DH, Gainche L, Sena-Esteves M, Curry WT Jr, Carter BS, Krichevsky AM and Breakefield XO: Glioblastoma microvesicles transport RNA and proteins that promote tumour growth and provide diagnostic biomarkers. Nat Cell Biol 10: 1470-1476, 2008.

67. Valadi H, Ekstrom K, Bossios A, Sjostrand M, Lee JJ and Lotvall JO: Exosome-mediated transfer of mRNAs and microRNAs is a novel mechanism of genetic exchange between cells. Nat Cell Biol 9: 654-659, 2007.

68. Pigati L, Yaddanapudi SC, Iyengar R, Kim DJ, Hearn SA, Danforth D, Hastings ML and Duelli DM, et al: Selective release of microRNA species from normal and malignant mammary epithelial cells. PLoS One 5: e13515, 2010.

69. Hu Z, Chen X, Zhao Y, Tian T, Jin G, Shu Y, Chen Y, Xu L, Zen $\mathrm{K}$, Zhang $\mathrm{C}$ and Shen $\mathrm{H}$ : Serum microRNA signatures identified in a genome-wide serum microRNA expression profiling predict survival of non-small-cell lung cancer. J Clin Oncol 28: 1721-1726, 2010.

70. Farsinejad S, Gheisary Z, Ebrahimi Samani S and Alizadeh AM: Mitochondrial targeted peptides for cancer therapy. Tumour Biol 36: 5715-5725, 2015.

71. Fulda S, Galluzzi L and Kroemer G: Targeting mitochondria for cancer therapy. Nat Rev Drug Discov 9: 447-464, 2010. 
72. Lafanechere L, Courtay-Cahen C, Kawakami T, Jacrot M, Rüdiger M, Wehland J, Job D and Margolis RL: Suppression of tubulin tyrosine ligase during tumor growth. J Cell Sci 111: 171-181, 1998

73. Wei S, Wang Y, Xu H and Kuang Y: Screening of potential biomarkers for chemoresistant ovarian carcinoma with miRNA expression profiling data by bioinformatics approach. Oncol Lett 10: 2427-2431, 2015.

74. Chua MM, Ortega CE, Sheikh A, Lee M, Abdul-Rassoul H, Hartshorn KL and Dominguez I: CK2 in cancer: Cellular and biochemical mechanisms and potential therapeutic target. Pharmaceuticals (Basel) 10: E18, 2017.

75. Ortega CE, Seidner Y and Dominguez I: Mining CK2 in cancer. PLoS One 9: e115609, 2014.

76. Abdel-Magid AF: Inhibition of CK2: An attractive therapeutic target for cancer treatment. ACS Med Chem Lett 4: 1131-1132, 2013.

77. Bae JS, Park SH, Jamiyandorj U, Kim KM, Noh SJ, Kim JR, Park HJ, Kwon KS, Jung SH, Park HS, et al: CK2 $\alpha /$ CSNK2A1 phosphorylates SIRT6 and is involved in the progression of breast carcinoma and predicts shorter survival of diagnosed patients Am J Pathol 186: 3297-3315, 2016.

78. Rabjerg M, Bjerregaard H, Halekoh U, Jensen BL, Walter S and Marcussen N: Molecular characterization of clear cell renal cell carcinoma identifies CSNK2A1, SPP1 and DEFB1 as promising novel prognostic markers. APMIS 124: 372-383, 2016.

79. Kulbe H, Iorio F, Chakravarty P, Milagre CS, Moore R, Thompson RG, Everitt G, Canosa M, Montoya A, Drygin D, et al: Integrated transcriptomic and proteomic analysis identifies protein kinase CK2 as a key signaling node in an inflammatory cytokine network in ovarian cancer cells. Oncotarget 7 : 15648-15661, 2016.

80. Srivastava R, Akthar S, Sharma R and Mishra S: Identification of Ellagic acid analogues as potent inhibitor of protein Kinase CK2: A chemopreventive role in oral Cancer. Bioinformation 11: 21-26, 2015.

81. Chatterjee A, Chatterjee U and Ghosh MK: Activation of protein kinase CK2 attenuates FOXO3a functioning in a PML-dependent manner: Implications in human prostate cancer. Cell Death Dis 4: e543, 2013.
82. Schneider CC, Kartarius S, Montenarh M, Orzeszko A and Kazimierczuk Z: Modified tetrahalogenated benzimidazoles with CK2 inhibitory activity are active against human prostate cancer cells LNCaP in vitro. Bioorg Med Chem 20: 4390-4396, 2012.

83. Nelson N, Szekeres K, Iclozan C, Rivera IO, McGill A, Johnson G, Nwogu O and Ghansah T: Apigenin: Selective CK2 inhibitor increases Ikaros expression and improves $\mathrm{T}$ cell homeostasis and function in murine pancreatic cancer. PLoS One 12: e0170197, 2017.

84. Benavent Acero F, Capobianco CS, Garona J, Cirigliano SM, Perera Y, Urtreger AJ, Perea SE, Alonso DF and Farina HG: CIGB-300, an anti-CK2 peptide, inhibits angiogenesis, tumor cell invasion and metastasis in lung cancer models. Lung cancer 107: 14-21, 2017.

85. Ku MJ, Park JW, Ryu BJ, Son YJ, Kim SH and Lee SY: CK2 inhibitor CX4945 induces sequential inactivation of proteins in the signaling pathways related with cell migration and suppresses metastasis of A549 human lung cancer cells. Bioor Med Chem Lett 23: 5609-5613, 2013

86. Zhou Y, Li K, Zhang S, Li Q, Li Z, Zhou F, Dong X, Liu L, Wu G and Meng R: Quinalizarin, a specific CK2 inhibitor, reduces cell viability and suppresses migration and accelerates apoptosis in different human lung cancer cell lines. Indian J Cancer 52 (Suppl 2): e119-e124, 2015.

87. So KS, Rho JK, Choi YJ, Kim SY, Choi CM, Chun YJ and Lee JC: AKT/mTOR down-regulation by CX-4945, a CK2 inhibitor, promotes apoptosis in chemorefractory non-small cell lung cancer cells. Anticancer Res 35: 1537-1542, 2015.

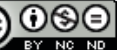

This work is licensed under a Creative Commons Attribution-NonCommercial-NoDerivatives 4.0 International (CC BY-NC-ND 4.0) License. 